\title{
Synthesis of (3Z)-Dodecenyl-(E)-2-butenoate, the Pheromone of Sweet Potato Weevil
}

\section{S. Mithran and A. S. Subbaraman*}

Bio-Organic Division, Bhabha Atomic Research Centre, Mumbai - 400 085, India

Fax: 91-22-5560750, E-mail: bod@magnum.barc.ernet.in

*Author to whom correspondence should be addressed.

Received: 15 January 1998 / Accepted: 13 May 1999 / Published: 16 May 1999

\begin{abstract}
A practical synthesis of the title pheromone has been developed. The key feature of the synthesis was the fixation of the required olefin geometry via a cis-selective Wittig reaction and use of commercially available starting materials to prepare the required synthons.
\end{abstract}

Keywords: sweet potato weevil, insect pheromone, synthesis.

\section{Introduction}

Sweet potato, primarily grown in the tropics, is one of the most important root crops in the world, surpassed only by potato. Its production and storage are strongly hampered [1] by the weevil, Cylas formicarius elegantulus which is a serious insect pest prevalent in India. The virgin female weevils secrete [2] (3Z)-dodecenyl (E)-2-butenoate (9) as the pheromone. Some other agriculturally important insects viz. the potato and sugar beet moths, Scrobipalpopsis solanivora [3] and Scrobipalpa ocetuatella [4] respectively secrete analogous compounds viz. the corresponding (3E)-acetate as their pheromone components. In addition, these $\mathrm{C}_{12}$-esters also constitute [5] synthetic attractants for the Reticulitermes termites. Our interest for the field control of the weevil has led to a novel preparation of 9, whose synthesis has already been described [2,6-8]. Amongst these, Heath et al. [2] have used the potential carcinogenic compounds like HMPA and ethylene oxide in their synthesis. The Wittig-based

(C) 1999 by the authors. Reproduction of this article, by any means, is permitted for noncommercial purposes. 
synthesis by a Chinese group [6] has been published with no technical detail. Another synthesis [8] on the other hand, employed expensive 3-butyn-1-ol as the starting material. Moreover, preparation of the alkynol in the laboratory often leads to poor yield in view of its high water solubility. In contrast, the present route does not involve any hazardous and /or expensive chemicals and furnishes the target pheromone in yield comparable with the earlier routes.

As discussed earlier, our main objective was to develop a multi-gram synthesis for the pheromone 9. To this end, we have already reported [7] two independent approaches via acetylenic route and Doebner condensation respectively. While the former led to a modest yield, the latter was primarily targeted to the corresponding ( $3 E$ )-compound and its elaboration to 9 involved too many steps to be suitable for a practical synthesis. For the synthesis, a stereoselective Wittig route involving $\mathrm{C}_{9}+\mathrm{C}_{3}$ combination seemed ideal, especially as the required $\mathrm{C}_{9}$-aldehyde moiety is amenable from many natural fatty acids viz. oleic acid (1). The bifunctional $\mathrm{C}_{3}$-unit can also be easily prepared from acrolein, another commercially available material. (Scheme 1.). Thus, the acid $\mathbf{1}$ was first dihydroxylated [9] with $\mathrm{HCO}_{3} \mathrm{H}$ to the diol acid $\mathbf{2 a}$. After esterification to $\mathbf{2 b}$, the diol function was cleaved with $\mathrm{NaIO}_{4}$. The required aldehyde 3 was easily separated from the ester component $\mathbf{4}$ by distillation.
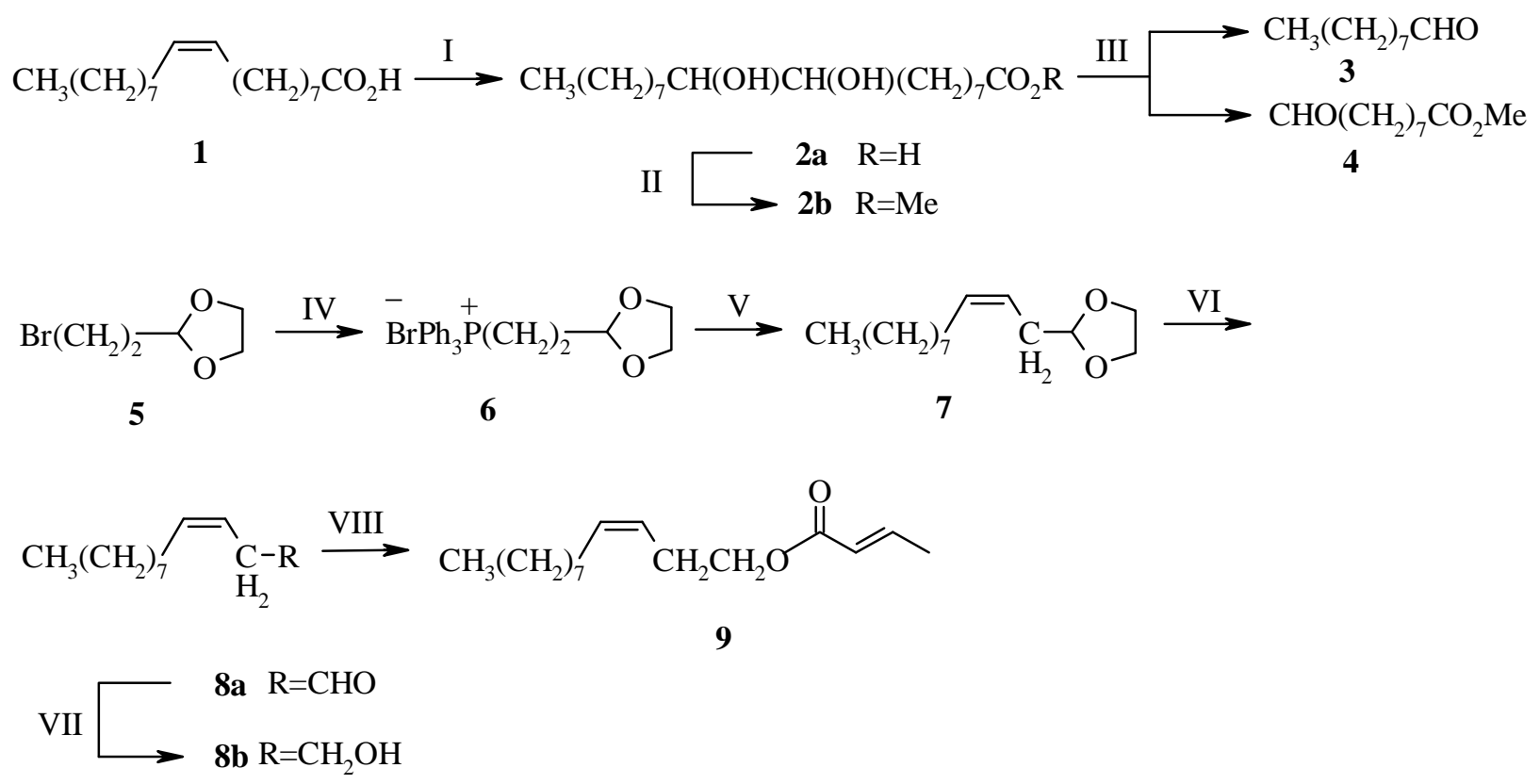

Scheme 1. I) $\mathrm{HCO}_{3} \mathrm{H}$; $\mathrm{KOH}$, II) $\mathrm{MeOH} / \mathrm{H}^{+}$, III) $\mathrm{NaIO}_{4} / \mathrm{CH}_{3} \mathrm{CN}-\mathrm{H}_{2} \mathrm{O}$, IV) $\mathrm{Ph}_{3} \mathrm{P} / \mathrm{CH}_{3} \mathrm{CN} /$, V) Dimsyl ion/ 3, VI) THF/ HOAc/ $\mathrm{H}_{2} \mathrm{O}$, VII) $\mathrm{NaBH}_{4} / \mathrm{MeOH}$, VIII)Crotonyl chloride/ Py.

Conversion of the Wittig salt 6 of the bromoacetal 5 [10] to the corresponding ylide with dimsyl ion as the base [10], followed by reaction with 3 gave the olefinic acetal 7. Hydrolysis of 7 proved difficult. The best result was obtained by refluxing its solution in THF-HOAc- $\mathrm{H}_{2} \mathrm{O}$. Upon reduction of the resultant aldehyde 8a with $\mathrm{NaBH}_{4}$, the known [5,6,11] alcohol $\mathbf{8 b}$ was obtained. Acylation with cro- 
tonyl chloride via a conventional procedure [7,8] gave the title pheromone $\mathbf{9}$ whose properties (IR, NMR, BP) were in agreement with those reported previously. [7,8,11].

\section{Experimental}

All the boiling points were uncorrected. The IR spectra were scanned with a Perkin-Elmer spectrophotometer model 837. The ${ }^{1} \mathrm{H}$ - and ${ }^{13} \mathrm{C}$-NMR spectra were recorded in $\mathrm{CDCl}_{3}$ (unless specified otherwise) with a Bruker AC-200 (200 MHz) instrument. The GLC analyses were carried out using Shima-

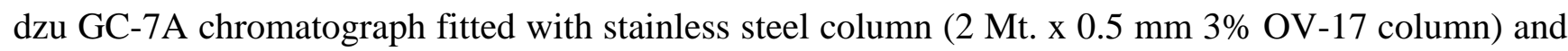
flame ionization detector. The mass spectrum was recorded with a Shimadzu QP-1000 mass spectrograph at $70 \mathrm{eV}$. Anhydrous reactions were carried out under Ar using freshly dried solvents. The organic extracts were dried over anhydrous $\mathrm{Na}_{2} \mathrm{SO}_{4}$.

\section{Methyl 9,10-Dihydroxyoctadecanoate (2b)}

Dihydroxylation of oleic acid $1(25.0 \mathrm{~g}, 0.88 \mathrm{~mol})$ was carried out by the slow addition of $\mathrm{HCO}_{3} \mathrm{H}$ [prepared from $40 \% \mathrm{H}_{2} \mathrm{O}_{2}(20 \mathrm{~mL})$ and $\mathrm{HCO}_{2} \mathrm{H}(125 \mathrm{~mL})$ at $0{ }^{\circ} \mathrm{C}$ ] followed by stirring for $8 \mathrm{~h}$ at $40{ }^{\circ} \mathrm{C}$ and at room temperature overnight. The mixture was distilled in vacuo $(10 \mathrm{~mm})$ and the residue was diluted with water and extracted with ether. The ethereal layer was washed with water, dried $\left(\mathrm{MgSO}_{4}\right)$ and concentrated. The residue was hydrolyzed with $5 \%$ aqueous $\mathrm{KOH}(200 \mathrm{~mL})$ on a steam bath for 1 $\mathrm{h}$, cooled and poured into excess cold dil. $\mathrm{HCl}(1 \mathrm{~N})$ under vigorous stirring (maintaining the temperature $\sim 20{ }^{\circ} \mathrm{C}$ ). The product was isolated by extraction with ether followed by washing with water, drying and concentration of the extract. The crude diol acid 2a was recrystallized from EtOAc. yield: 22.3 g (80\%); mp $91{ }^{\circ} \mathrm{C}$, (lit. [12] mp $95{ }^{0} \mathrm{C}$ ); IR: 3600-3400, 3340, 2660, $1700 \mathrm{~cm}^{-1} ;{ }^{1} \mathrm{H}-\mathrm{NMR}$ (DMSO): $\delta$ 0.9 (distorted t, 3H), 1.3 (br. s, 26H), 1.9-2.1 (m, 2H), 2.61 (br. s, $\mathrm{D}_{2} \mathrm{O}$ exchangeable, 2H), 3.6-3.9 (m, 2H), 8.1 (br. s, $\mathrm{D}_{2} \mathrm{O}$ exchangeable, $\left.1 \mathrm{H}\right)$.

A solution of $2 \mathrm{a}(20.0 \mathrm{~g}, 0.063 \mathrm{~mol})$ in $\mathrm{MeOH}(150 \mathrm{~mL})$ containing para-toluenesulfonic acid (PTS) $(0.2 \mathrm{~g}$ ) was refluxed for $6 \mathrm{~h}$. Most of the solvent was removed in vacuo. The residue was dissolved in ether and the ether layer was washed with water and brine and dried. Removal of solvent furnished the pure diol-ester $\mathbf{2 b}$ as a low melting solid. yield: $20.6 \mathrm{~g}$ ( quantitative); IR: 3360, 1750 $\mathrm{cm}^{-1}$; ${ }^{1} \mathrm{H}-\mathrm{NMR}: \delta 0.9$ (distorted t, 3H), 1.33 (m, 26H), 2.1-2.5 (m, 2H), 2.7 (br. s, $\mathrm{D}_{2} \mathrm{O}$ exchangeable, $2 \mathrm{H}), 3.2-3.6(\mathrm{~m}, 2 \mathrm{H}), 3.65(\mathrm{~s}, 3 \mathrm{H})$.

\section{Nonanal (3)}

To a stirred solution of the diol $\mathbf{2 b}(16.5 \mathrm{~g}, 0.05 \mathrm{~mol})$ in $\mathrm{CH}_{3} \mathrm{CN}(50 \mathrm{~mL})-\mathrm{CH}_{2} \mathrm{Cl}_{2}(50 \mathrm{~mL})-\mathrm{H}_{2} \mathrm{O}(10$ $\mathrm{mL})$ at $25{ }^{\circ} \mathrm{C}$ was added $\mathrm{NaIO}_{4}(11.0 \mathrm{~g}, 0.05 \mathrm{~mol})$ in portions. After stirring for $2 \mathrm{~h}$, the reaction mixture was filtered, the filtrate concentrated in vacuo and the residue extracted with ether. The ethereal 
extract was washed successively with aqueous $10 \% \mathrm{Na}_{2} \mathrm{SO}_{3}$, water, aqueous $10 \% \mathrm{Na}_{2} \mathrm{~S}_{2} \mathrm{O}_{3}$, water and brine. After drying, the organic extract was concentrated and the crude product mixture was fractionally distilled to afford the aldehyde 3 and the ester aldehyde 4.

3: yield: $5.7 \mathrm{~g}$ (79.2\%); bp. 80-85 ${ }^{0} \mathrm{C} / 10 \mathrm{~mm}$; IR: 2930, 2860, 2710, $1730 \mathrm{~cm}^{-1}$; ${ }^{1} \mathrm{H}-\mathrm{NMR}: \delta 0.9$ (distorted t, 3H), 1.4-1.8 (m, 12H), 2.0-2.3 (m, 2H), $9.1(\mathrm{t}, J=1.5 \mathrm{~Hz}, 1 \mathrm{H})$.

4: yield: $5.85 \mathrm{~g}(63 \%)$; bp $70-75^{\circ} \mathrm{C} / 2.5 \mathrm{~mm}$.

\section{3-Bromopropanal Ethyleneglycol Acetal (5)}

$\mathrm{HBr}$ gas [generated from $\mathrm{Br}_{2}(51.5 \mathrm{~mL}, 1.0 \mathrm{~mol})$ to tetralin $(37.5 \mathrm{~mL}, 0.275 \mathrm{~mol})$ ] was bubbled through a stirred and cooled $\left(0{ }^{\circ} \mathrm{C}\right)$ solution of acrolein $(67.5 \mathrm{~mL}, 1.0 \mathrm{~mol})$ in $\mathrm{CH}_{2} \mathrm{Cl}_{2}(500 \mathrm{~mL})$. Ethylene glycol (66.6 mL, $1.2 \mathrm{~mol})$ was then added to it and the mixture stirred at room temperature overnight. It was cooled to $0{ }^{\circ} \mathrm{C}$, made basic with $10 \%$ aqueous $\mathrm{NaHCO}_{3}$ and extracted with ether. The organic layer was washed with water, dried, concentrated and distilled to give $\mathbf{5}$ as a colourless liquid. yield: $94.3 \mathrm{~g}$ (52\%); bp 68-70 ${ }^{0} \mathrm{C} / 5 \mathrm{~mm}$, (lit. [10] bp.68-70 ${ }^{\circ} \mathrm{C} / 5 \mathrm{~mm}$ ); IR: 1410, 1360, 1265, 1210, 1030, 880, $820 \mathrm{~cm}^{-1} .{ }^{1} \mathrm{H}-\mathrm{NMR}: \delta 1.95-2.35(\mathrm{~m}, 2 \mathrm{H}), 3.4(\mathrm{t}, J=6 \mathrm{~Hz}, 2 \mathrm{H}), 3.7-4.0(\mathrm{~m}, 4 \mathrm{H}), 4.93(\mathrm{t}, J=$ $4 \mathrm{~Hz}, 1 \mathrm{H})$.

\section{1,3-Dioxolan-2-yl-methyltriphenylphosphonium Bromide (6)}

A solution of triphenylphosphine $(28.4 \mathrm{~g}, 0.11 \mathrm{~mol})$ and the bromide $5(18.1 \mathrm{~g}, 0.1 \mathrm{~mol})$ in $\mathrm{CH}_{3} \mathrm{CN}$ $(200 \mathrm{~mL})$ was refluxed for $24 \mathrm{~h}$. After removing most of the solvent, the mixture was diluted with benzene $(300 \mathrm{~mL})$ and refluxed for $3 \mathrm{~h}$. After cooling the upper solvent layer was decanted to give 6 as a yellow-brown thick mass which was used as such for the next step. yield: $27.2 \mathrm{~g}(61.4 \%)$.

\section{(3Z)-Dodecenal (8a)}

To a stirred solution of dimsyl anion [prepared by heating $\mathrm{NaH}(2.22 \mathrm{~g}, 0.042 \mathrm{~mol}, 50 \%$ dispersion in oil) in DMSO $(75 \mathrm{~mL})$ at $65{ }^{\circ} \mathrm{C}$ for $1 \mathrm{~h}$ ] was added the phosphonium salt $6(18.58 \mathrm{~g}, 0.042 \mathrm{~mol})$ at room temperature. After stirring for $1 \mathrm{~h}$, the aldehyde $3(5.4 \mathrm{~g}, 0.038 \mathrm{~mol})$ in DMSO (15 mL) was added to the resulting orange ylide solution. Stirring was continued for $16 \mathrm{~h}$ at the same temperature, the mixture poured in large excess ice-water and extracted with ether. The ethereal layer was washed with water and brine and dried. Removal of solvent gave a residue which was thoroughly extracted with hexane and the extract after concentration subjected to column chromatography (silicagel, 0-10\% EtOAc/hexane) to furnish the acetal 7. yield: $4.17 \mathrm{~g}(48.5 \%)$; bp $100{ }^{\circ} \mathrm{C}$ (bath) $/ 0.5 \mathrm{~mm}$; IR: 3010 , 1460, $1030 \mathrm{~cm}^{-1}$; ${ }^{1} \mathrm{H}-\mathrm{NMR}$ : $\delta 0.9$ (distorted t, 3H), 1.2-1.7 (m, 12H), 2.0-2.1 (m, 4H), 3.8-4.0 (m, 4H), 4.8 (distorted $\mathrm{t}, 1 \mathrm{H}), 5.3-5.5(\mathrm{~m}, 2 \mathrm{H})$.

A solution of $7(3.84 \mathrm{~g}, 0.017 \mathrm{~mol})$ in THF $(35 \mathrm{~mL}), \mathrm{HAc}(8.5 \mathrm{~mL})$ and $\mathrm{H}_{2} \mathrm{O}(8.5 \mathrm{~mL})$ was heated 
on a water bath for $3 \mathrm{~h}$. Most of the solvent was removed, water added and the residue extracted with ether. The ether layer was washed with water and brine and dried. Removal of solvent gave the aldehyde 8a. yield: $2.38 \mathrm{~g}$ (77.1\%); IR: 2720, $1715 \mathrm{~cm}^{-1}$.

\section{(3Z)-Dodecen-1-ol (8b)}

To a cooled $\left(0{ }^{\circ} \mathrm{C}\right)$ and stirred solution of compound $8 \mathbf{a}(2.3 \mathrm{~g}, 0.013 \mathrm{~mol})$ in $\mathrm{MeOH}(20 \mathrm{~mL})$ was added $\mathrm{NaBH}_{4}(0.5 \mathrm{~g}, 0.013 \mathrm{~mol})$ in portions. After $1.5 \mathrm{~h}$, when the reaction was complete ( $c f$. TLC), it was quenched with $\mathrm{NH}_{4} \mathrm{Cl}(\mathrm{s})$, concentrated and extracted with ether. The ether layer was washed with water, brine and dried. After concentration, the residue was distilled to afford 8b. yield: $1.95 \mathrm{~g}$ (81.5\%); bp 90-110 ${ }^{\circ} \mathrm{C} / 0.1 \mathrm{~mm}$, (lit.[11] bp 67-70 ${ }^{\circ} \mathrm{C} / 0.05 \mathrm{~mm}$; IR: 3350, 1460, $1050 \mathrm{~cm}^{-1}$; ${ }^{1} \mathrm{H}-\mathrm{NMR}$ : $\delta 0.9$ (t, $J=6 \mathrm{~Hz}, 3 \mathrm{H}), 1.30$ (br. s, 12H), 2.0-2.6 (m, 4H), $2.9\left(\mathrm{~s}, 1 \mathrm{H}, \mathrm{D}_{2} \mathrm{O}\right.$ exchangeable), $3.63(\mathrm{t}, J=$ $7 \mathrm{~Hz}, 2 \mathrm{H}), 5.2-5.7(\mathrm{~m}, 2 \mathrm{H})$.

\section{(3Z)-Dodec-3-enyl-(E)-2-butenoate (9)}

A mixture of $\mathbf{8 b}(1.84 \mathrm{~g}, 0.01 \mathrm{~mol})$, crotonyl chloride $(2.09 \mathrm{~g}, 0.02 \mathrm{~mol})$ and pyridine $(4 \mathrm{~mL})$ in $\mathrm{CH}_{2} \mathrm{Cl}_{2}(15 \mathrm{~mL})$ was stirred at room temperature for $12 \mathrm{~h}$. Water $(20 \mathrm{~mL})$ was added and the mixture was extracted with ether. The extract was washed with aqueous $\mathrm{NaHCO}_{3}(10 \%)$, water, aqueous $\mathrm{HCl}$ $(2 \mathrm{~N})$, water and brine and finally dried. Usual isolation followed by column chromatography (silica gel, hexane) afforded pure 9. yield: $1.81 \mathrm{~g}$ (72\%); bp 135-140 ${ }^{\circ} \mathrm{C}$ (bath)/2 mm, (lit. [11] bp105-109 ${ }^{0} \mathrm{C} / 0.1 \mathrm{~mm}$ ); GLC (temp. prog. $100-250{ }^{0} \mathrm{C} @ 8{ }^{\circ} \mathrm{C} / \mathrm{min}$ ): $\mathrm{R}_{\mathrm{t}}=14.21$ (94.1\%); IR: 3010, 1740, 1680 and $980 \mathrm{~cm}^{-1}$; ${ }^{1} \mathrm{H}-\mathrm{NMR}$ : $\delta 0.9(\mathrm{t}, 3 \mathrm{H}), 1.24$ (br. s, 12H), 1.6-2.5 (m, 7H), $4.1(\mathrm{t}, J=6 \mathrm{~Hz}, 2 \mathrm{H}), 5.3-5.9$ $(\mathrm{m}, 3 \mathrm{H}), 6.8-7.1(\mathrm{~m}, 1 \mathrm{H}) ;{ }^{13} \mathrm{C}$ NMR: $\delta 14.02,17.82,22.61,25.9,26.86,27.27,28.65,29.59,31.84$, $32.18,36.58,39.01,62.24,64.23,64.88,122.8,123.82,124.28,132.84,136.33,144.13,166.53$; MS (rel. int.): m/z 43 (49), 54 (87), 68 (100), 81 (59), 87 (43), 96 (41), 109 (15.7), 110 (14.9), 124 (10), 138 (11.6), 166 (24.3), $252\left(\mathrm{M}^{+}, 2.1\right), 253$ (4.3). Anal. Calcd. for $\mathrm{C}_{16} \mathrm{H}_{28} \mathrm{O}_{2}: \mathrm{C} 76.1 \%, \mathrm{H} 11.2 \%$; Found: C $76.3 \%, \mathrm{H} 11.3 \%$.

\section{References and Notes}

1. Martin, F. W. Proc. Am. Soc. Horti. Sci. Trop. Sect. 1983, $27 B, 61$.

2. Heath, R. R.; Coffelt, J. A.; Sonnet, P. E.; Proshold, F. I.; Dueben, B.; Tumlinson, J. H. J. Chem. Ecol. 1986, 12, 1489.

3. Nesbitt, B. F.; Beevor, P. S.; Cork, A.; Hall, D. R.; Murillo, R. M.; Leal, H. R. Entomol. Exp. Appl. 1985, 38, 81.

4. Wilemse, L. P. M.; Booji, C. J. H.; Voerman, S. J. Appl. Entomol. 1987, 103, 508.

5. Carvalho, J. F.; Prestwich, G. D. J. Org. Chem. 1984, 49, 1251. 
6. Handong, L.; Yanneng, D.; Hansheng, X.; Li, T.; Huisheng, Q. Youji Huaxue 1988, 8, 167, Chem. Abstr. 1989, 110, 23584x.

7. Pawar, A. S.; Chattopadhyay, S.; Mamdapur, V. R. Indian J. Chem. 1993, 32B, 463.

8. Mani, N. S.; Nair, M. S. Indian J. Chem. 1993, 32B, 1151.

9. Singh, A. N.; Mhaskar, V. V.; Sukhdev. Tetrahedron 1978, 34, 595.

10. Buchi, G.; Wuest, H. J. Org. Chem. 1969, 34, 1122.

11. Heath, R. R.; Coffelt, J. A.; Sonnet, P. E.; Proshold, F. I.; Dueben, B.; Tumlinson, J. H. J. Chem. Ecol. 1986, 12, 489.

12. Doree, C.; Pepper, A. C. J . Chem. Soc. 1942, 477.

Samples Availability: Available from the authors.

(C) 1999 by the authors. Reproduction of this article, by any means, is permitted for noncommercial purposes. 